\title{
Tropical cyclone perceptions, impacts and adaptation in the Southwest Pacific: an urban perspective from Fiji, Vanuatu and Tonga
}

\author{
Andrew D. Magee ${ }^{1}$, Danielle C. Verdon-Kidd ${ }^{1}$, Anthony S. Kiem ${ }^{2}$, and Stephen A. Royle ${ }^{3,4}$ \\ ${ }^{1}$ Environmental and Climate Change Research Group (ECCRG), School of Environmental and Life Sciences, Faculty of \\ Science and Information Technology, The University of Newcastle, Callaghan, NSW, 2308, Australia \\ ${ }^{2}$ Centre for Water, Climate and Land-Use (CWCL), Faculty of Science and Information Technology, The University of \\ Newcastle, Callaghan, NSW, 2308, Australia \\ ${ }^{3}$ Kagoshima University Research Centre for the Pacific Islands, Kagoshima University, Kagoshima, Japan \\ ${ }^{4}$ School of Geography, Archaeology and Palaeoecology (GAP), Queen's University Belfast, Belfast, UK
}

Correspondence to: Andrew D. Magee (andrew.magee@uon.edu.au)

Received: 23 October 2015 - Published in Nat. Hazards Earth Syst. Sci. Discuss.: 26 November 2015

Revised: 14 April 2016 - Accepted: 1 May 2016 - Published: 12 May 2016

\begin{abstract}
The destruction caused by tropical cyclone (TC) Pam in March 2015 is considered one of the worst natural disasters in the history of Vanuatu. It has highlighted the need for a better understanding of TC impacts and adaptation in the Southwest Pacific (SWP) region. Therefore, the key aims of this study are to (i) understand local perceptions of TC activity, (ii) investigate impacts of TC activity and (iii) uncover adaptation strategies used to offset the impacts of TCs. To address these aims, a survey (with 130 participants from urban areas) was conducted across three SWP small island states (SISs): Fiji, Vanuatu and Tonga (FVT). It was found that respondents generally had a high level of risk perception and awareness of TCs and the associated physical impacts, but lacked an understanding of the underlying weather conditions. Responses highlighted that current methods of adaptation generally occur at the local level, immediately prior to a TC event (preparation of property, gathering of food, finding a safe place to shelter). However higher level adaptation measures (such as the modification to building structures) may reduce vulnerability further. Finally, we discuss the potential of utilising weather-related traditional knowledge and nontraditional knowledge of empirical and climate-model-based weather forecasts to improve TC outlooks, which would ultimately reduce vulnerability and increase adaptive capacity. Importantly, lessons learned from this study may result in
\end{abstract}

the modification and/or development of existing adaptation strategies.

\section{Introduction}

The Southwest Pacific (SWP), home to 15 small island states (SISs) and approximately 2.7 million people, is a vast area, vulnerable to the impact of tropical cyclones (TCs). Delicate environments and fragile economies underpin the SWP, where TCs account for $76 \%$ of reported natural disasters in the region (World Bank, 2006). Environmentally, the SWP is compounded by an unfavourable shoreline to land area ratio (Barnett, 2001) and a combination of low-lying coral atolls, reef islands and volcanically composed islands (Connell, 2013). Economically, the region is characterised by small populations, limited resources and a dependency on primary industries (Connell, 2013), specifically subsistence farming (Mataki et al., 2006; Mimura, 1999). Given these vulnerabilities and the spatiotemporal variability of TC activity, the impacts on the SWP are significant. Since 1950, TCs have impacted 2.5 million people and resulted in 1400 fatalities (World Bank, 2006). For example, TC Kina (December 1992/January 1993) caused an estimated USD 120 million in damages ( $2 \%$ of Fiji's GDP) and resulted in 26 fatalities (Salinger and Lefale, 2005). TC Evan (December 2012) re- 
sulted in an estimated USD 315 million of damage and 14 fatalities across Samoa, Fiji, Wallis and Futuna, Tonga and New Zealand (GOF, 2013). More recently, TC Pam (March 2015), a severe category 5 TC resulted in damages exceeding USD 360 million, with 11 fatalities (Nishijima et al., 2015). These are only a few of the many TCs that occur in the SWP each year.

The impacts of TCs in the SWP mean that viable and effective adaptation and mitigation strategies are needed (Mataki et al., 2006; Mortreux and Barnett, 2009; Rasmussen et al., 2009). El-Masri and Tipple (2002) discuss how such methods should be multidisciplinary and based on a range of engineering, land management and social and economic improvements. One such measure relevant to this study includes the use of community participation. Gathering the opinions and perceptions of extreme events from the people at risk of natural disasters provides emergency management agencies the opportunity to assess and modify risk management procedures (Bird, 2009). The benefits of this information, which can result in a more resilient nation that is less vulnerable to the threat of an extreme event is demonstrated by Wachinger et al. (2010, 2013). Across the world, surveys have also been used to understand public perception on a range of environmental extremes and hazards including drought (Ashraf and Routray, 2013; Udmale et al., 2014), climate change (Acquah, 2011; Deressa et al., 2011; Manandhar et al., 2011, 2015; Vedwan and Rhoades, 2001) and tropical cyclones (Li, 2009). Weather-related traditional knowledge (TK) has also been shown to be a cost-effective, participatory and sustainable method of adaptation (Nyong et al., 2007; Robinson and Herbert, 2011). The use of weather-related TK involves documenting the response of the land (flora and fauna) and sea to specific meteorological phenomena. Numerous studies have demonstrated the usefulness of TK in improving our understanding of environmental prediction and meteorological phenomena in the South Pacific (Chand et al., 2014; Lefale, 2009; Waiwai and Malsale, 2013), and in other areas around the world including, Africa (Chang'a et al., 2010; Nyong et al., 2007; Shoko and Shoko, 2013), Asia (Chinlampianga, 2011; Roder et al., 2015) and Australia (Green et al., 2010). These studies demonstrate that personal experiences and knowledge of extreme events (such as TCs) from those living in affected regions represents a crucial source of information. It offers scientists, policymakers and social development workers the opportunity to incorporate comprehensive insight into local-scale weather systems, impacts and coping strategies.

Fiji, Vanuatu and Tonga (FVT) are three SISs that are highly vulnerable to the impacts of TCs. Of the 12.9 TCs that occur in the SWP per year, 3.3, 3.9 and 2.7 TCs cross within $5^{\circ}(550 \mathrm{~km})$ of FVT respectively (Diamond et al., 2013). Vanuatu is considered the most vulnerable nation in the world to the threat of natural hazards (World Bank, 2015), and is the most economically disadvantaged country due to the impact of natural hazards (World Bank, 2006). Between
1950 and 2005, Vanuatu's losses due to natural hazards were equivalent to $30 \%$ of its GDP in disaster years (World Bank, 2006). Vanuatu's relative TC risk (a calculation of the exposure and vulnerability to TC activity) is the highest in the world (8/10), with 30-100 deaths per million per year (Peduzzi et al., 2012). Moreover, $100 \%$ of Vanuatu's population and GDP are located in a TC-prone area. The impact of TCs in Vanuatu are exacerbated by Vanuatu's medium $\mathrm{Hu}-$ man Development Index ranking (HDI; United Nations Development Program 2015), ranked 134 out of 188 countries and territories and GDP per capita of USD 3277. Fiji and Tonga are similarly vulnerable to TCs. Both have a relative TC risk of 7/10, a mortality risk of $10-100$ people per million and $100 \%$ of their population and GDP is situated in a TCprone area. However, in comparison with Vanuatu, the economic impact of TCs on Fiji and Tonga is quite different. Fiji and Tonga are considered high human development nations, ranked 90/188 and 100/188 respectively (United Nations Development Program, 2015), with a higher GDP per capita: USD 4375 (Fiji) and USD 4427 (Tonga). Between 1950 and 2005, natural disasters cost Fiji $7.7 \%$ and Tonga 14.2\% GDP during disaster years (World Bank, 2006).

Given the vulnerability of the FVT region to the impact of TCs, this study records TC-related experiences and perceptions of Ni-Vanuatu, Fijian and Tongan people from an urban perspective. Three themes are explored in this study: (i) how individuals perceive the processes that cause or are associated with TCs, (ii) how people are impacted by TCs, and (iii) adaptation strategies used to offset the impacts of TCs. We also explore a conceptual framework that has the potential of improving adaptation practices and strategies for disaster risk reduction (DRR) by using weather-related TK alongside more quantitative methods such as meteorology and weather forecasting (scientific knowledge - SK). Merging both forms of weather-related knowledge may assist meteorological offices, policymakers, disaster management organisations and aid agencies to be better prepared for a TC event.

\section{Methodology}

The FVT region was chosen as the case study area for this study (Fig. 1) due to its susceptibility to frequent TC events (Chand and Walsh, 2009; Diamond et al., 2013). The following urban locations were sampled across the FVT region. In Fiji, Lautoka, Nadi Town and Denaurau Island were sampled. Port-Vila and the village of Mele Maat were sampled in Vanuatu, and Nuku'Alofa in Tonga.

The survey is comprised of eight questions aimed to address the key research themes (see Table 1). Delivered verbally, the survey is composed of a mixture of closed (Q1$\mathrm{Q} 3)$ and open $(\mathrm{Q} 4-\mathrm{Q} 8)$ questions. The survey allowed the participants to share as much, or as little information as they wanted. Given the economic and social landscape of the 


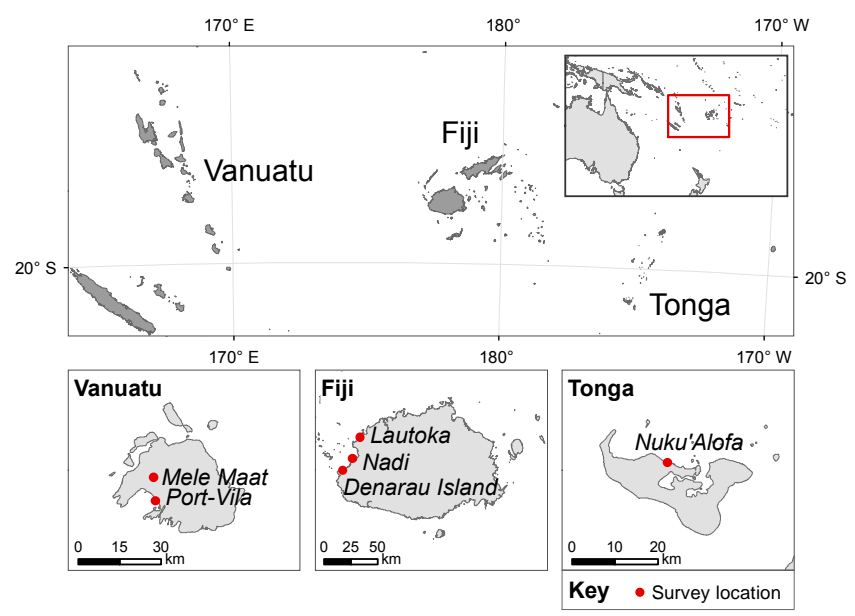

Figure 1. Map of study location and urban survey locations across Fiji, Vanuatu and Tonga (FVT region).

FVT, a feasibility study of the most effective way of recruiting participants was conducted (considering options such as face-to-face interviews, mail-out, online surveys or phone interviews). The research team established that a one-to-one verbal survey was most favourable, supported by Anderson (2003) who stated that "the preference is for "eyeball-toeyeball" contact or "face-to-face" interaction, making meetings, discussion and personal interaction critical. This type of communication helps to determine trust".

The survey was completed over a 3-week period in November 2013 in public areas around urban centres, for example, local markets, and transportation hubs around central business districts. Survey participants were selected based on age (over 18 years old) and the individuals' willingness to take part in the study. The FVT region is ethnically and culturally diverse, although all nations have English listed as one of their many official languages. Despite this, in a small number of cases, a language barrier (poor spoken English) meant that a participant could not fully engage in the survey. In some instances respondents were unable to answer all of the survey questions asked. This may be attributed to the fact that the participant did not understand the question, or the participant did not know how to answer the question. At times the interviewer elaborated or simplified questions to ensure the participant understood. In the case where participants were unable to answer a question, this was left blank.

\section{Qualitative analysis}

After data collection, responses recorded across the FVT region were transcribed into nVIVO, a qualitative data research software package (see Klint et al., 2012 for a similar methodology). nVIVO was used to explore relationships between words and identified key themes from the responses. Answers were subsequently sorted according to theme to enable analysis and interpretation.

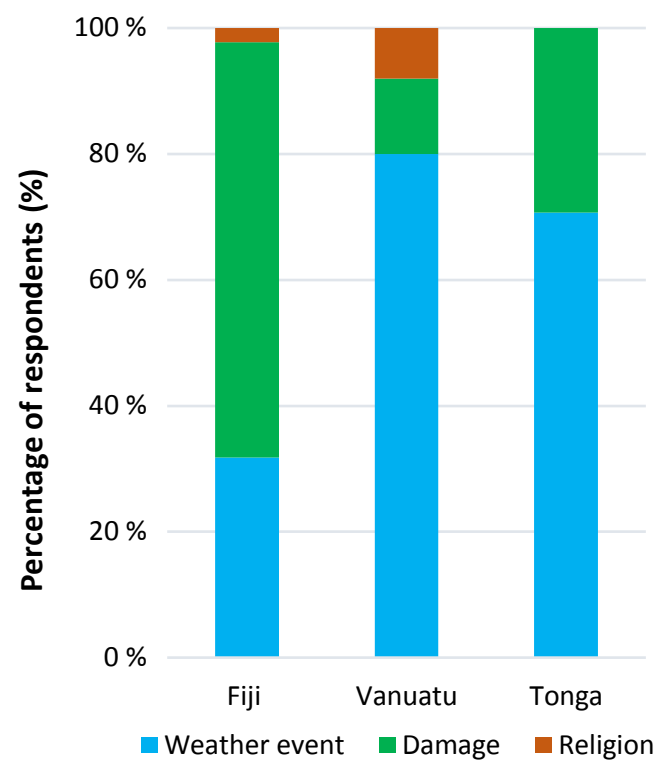

Figure 2. Percentage of responses to question 4: "What is your understanding of a tropical cyclone?"

For some responses, themes are presented graphically, and compared between island nations. Actual responses also appear in-text. Further, the impact of TCs on FVT is highlighted by the frequency of words, through the use of word clouds (e.g. McNaught and Lam, 2010; Kiem and Austin, 2013). Word clouds work on the principle of text size, with the text size proportional to the number of responses that use a particular word or phrase. Despite the benefits, there are also a number of limitations of using word clouds (Kiem and Austin, 2013), such as, words being used out of context, spelling mistakes or different synonyms for the same keyword.

\section{Results}

A total of 130 participants took part in the survey across the FVT region. Table 2 summarises the demographics of the sample population. A fairly equal representation of gender (52\% females, $48 \%$ males), occupation and age (mean age is 39 years - herein $39 \mathrm{Y}$ ) is reflected in the sample population. The number of participants varied for each study area (Fiji: 47, Vanuatu: 25, Tonga: 58).

\subsection{Local perceptions of tropical cyclones}

Question 4, "what is your understanding of a tropical cyclone?" (Table 1), assessed whether the population were aware of the physical processes and/or the impacts associated with TCs. Analysis of the responses highlighted two main themes that emerged from this question: 
Table 1. Survey questions.

\begin{tabular}{|c|c|c|c|}
\hline Question number & Question & Section/key areas & Type of question \\
\hline 1 & Occupation of participant & Demographic & Closed questions \\
\hline 2 & Age of participant & & \\
\hline 3 & How long have you lived here? & & \\
\hline 4 & $\begin{array}{l}\text { What is your understanding of a } \\
\text { tropical cyclone? }\end{array}$ & Perceptions of TCs & Open questions \\
\hline 5 & $\begin{array}{l}\text { How do tropical cyclones impact } \\
\text { you and your community? }\end{array}$ & Physical impact of TC activity & \\
\hline 6 & $\begin{array}{l}\text { How do you get information about } \\
\text { when a tropical cyclone is about to } \\
\text { hit? }\end{array}$ & TC-related adaptation strategies & \\
\hline 7 & $\begin{array}{l}\text { Is there any other information you } \\
\text { need to be better prepared for a } \\
\text { tropical cyclone? }\end{array}$ & & \\
\hline 8 & $\begin{array}{l}\text { What do you and your community } \\
\text { do to help reduce the impacts of } \\
\text { tropical cyclones? }\end{array}$ & & \\
\hline
\end{tabular}

Table 2. Demographics of participants.

\begin{tabular}{lllll}
\hline \multirow{2}{*}{ Number of participants } & & Fiji & Vanuatu & Tonga \\
\cline { 3 - 5 } Age & $18-30$ & 47 & 25 & 58 \\
& $31-40$ & 17 & 7 & 16 \\
& $41-50$ & 12 & 9 & 20 \\
& $51-60$ & 7 & 6 & 8 \\
& $60+$ & 8 & 2 & 11 \\
& Mean & 3 & 1 & 3 \\
Gender & Male \% & 40 & 38 & 39 \\
& Female \% & 60 & 36 & 43 \\
Occupation & \% unemployed/retired & 12.5 & 16.7 & 17.6 \\
& $\%$ primary & 53.1 & 41.6 & 50 \\
& $\%$ secondary & 0 & 4 & 2.9 \\
& $\%$ tertiary & 31.3 & 37.5 & 29.4 \\
& $\%$ quaternary & 3.1 & 0 & 0 \\
\hline
\end{tabular}

i. respondents who associate a TC with the weather conditions (meteorological/oceanographic) experienced during a TC event;

ii. respondents who focus on the physical impacts and damage associated with TCs (upon people and places); in some cases these responses disconnected the weather phenomenon from the impact.

The majority of respondents in Vanuatu (80\%) and Tonga (71\%) discussed the weather conditions and related meteorological and oceanographic conditions experienced during a TC event (Fig. 2). Many focused their answers on high wind speeds, significant rainfall, strong seas and potential storm surge caused by TCs. Many responses lacked detail, which may be an indication that individuals are unfamiliar with the physical processes underlying TCs, similar to the findings of Lefale (2009), who noted limited knowledge of weather phenomenon and the processes underlying them for inhabitants in the South Pacific. Some respondents even associated tectonic activity as having an active role in TC activity. Those who discussed the subsequent weather conditions were generally older (39Y) than those who discussed the subsequent impacts $($ Vanuatu $=33 \mathrm{Y}$, Tonga $=34 \mathrm{Y})$.

Although only $32 \%$ of responses from Fiji discussed the physical mechanisms underlying TC activity, responses were 
considerably more detailed than those from Vanuatu and Tonga. Some respondents noted that TCs are low-pressure systems and usually occur during hot and humid conditions. Many responses noted the canonical TC season of the SWP, which runs from November to April. The majority of respondents $(66 \%)$ discussed the damage associated with a TC event (discussed in more detail in Sect. 3.2). A small number of respondents, two from Vanuatu and one from Fiji believed that TCs were an "act of God". One respondent from Vanuatu stated that "God brings a cyclone to warrant change". Similarly, a study on seismic risk perception in Europe (Plapp and Werner, 2006) identified a number of respondents that believed God controlled the onset of seismic events to inflict punishment. As discussed by Solberg et al. (2010), a significant disconnect between reality (scientific knowledge) and lay interpretations of the earth's processes exists.

\subsection{Impacts of TCs on indigenous communities}

Question 5, "how do tropical cyclones impact you and your community?", assessed TC-related impacts. Responses are summarised in a word cloud (Fig. 3) for 40 of the most commonly used words across the FVT region. Responses from the FVT are discussed in turn below and compared to objective data from a number of TCs that impacted the region.

\subsubsection{Fiji}

The majority of Fijian responses (78\%) discussed damage to personal property and/or damage to housing/gardens. One participant commented, "the impact is very bad. The tropical cyclone destroys our houses, water tanks, gardens and falls all of our trees". Other responses also highlighted how high winds can cause trees to fall onto houses and buildings. Of the 8497 homes damaged by TC Evan, 2094 were completely destroyed $(25 \%)$, which cost an estimated FJD 50 million $^{1}$ (USD 23 million) to repair. A number of participants (34\%) also noted the psychological impact of TCs, including shock, distress, disappointment and fear. Displacement and homelessness were particular themes featured in many responses, caused by damage to homes or the secondary impacts of flooding. A fewer number of people $(20 \%)$ mentioned the impact on infrastructure including, damage to roads, power cuts and prolonged damage to power supplies hampering the relief effort. Some respondents highlighted the severe damage that can occur across the Mamanuca and Yasawa Island groups (to the northwest of Viti Levu), given their high shoreline to land area ratio, low-lying relief and relative isolation from the larger islands of Viti Levu and Vanua Levu.

The SWP islands are very much reliant on subsistence farming (Mataki et al., 2006; Mimura, 1999). Indeed, the impact of TCs on the agricultural sector of Pacific Island nations represents $22 \%$ of the overall economic impact (between 2003 and 2013; Food and Agriculture Organisation of

\footnotetext{
${ }^{1} 1 \mathrm{FJD}=0.46 \mathrm{USD}-$ correct as of 14 January 2016
}

(a)
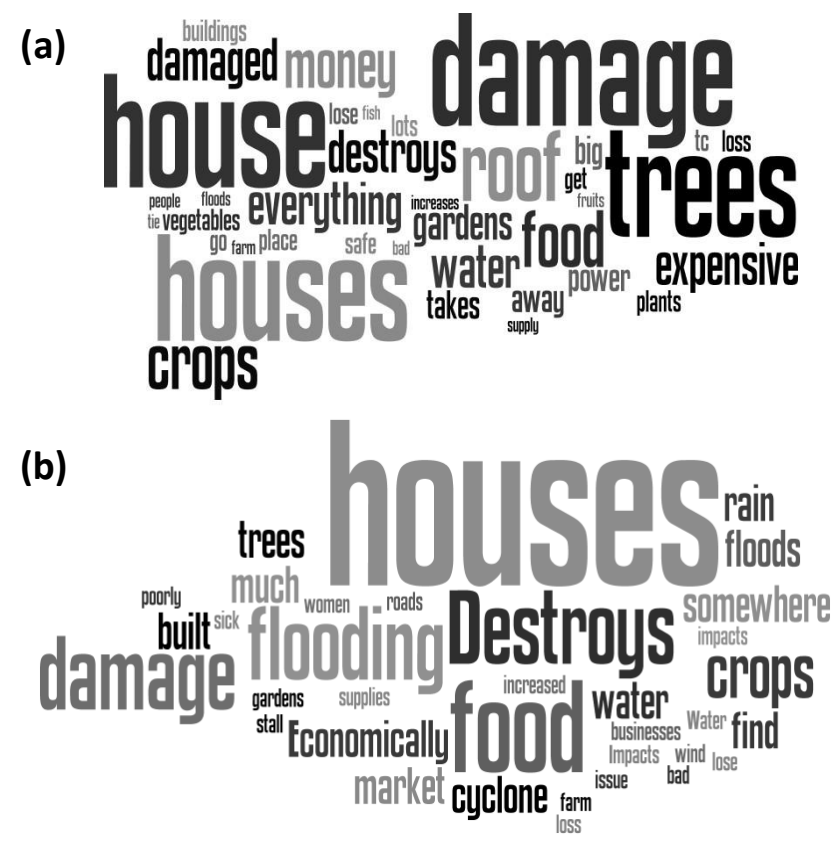

(c)

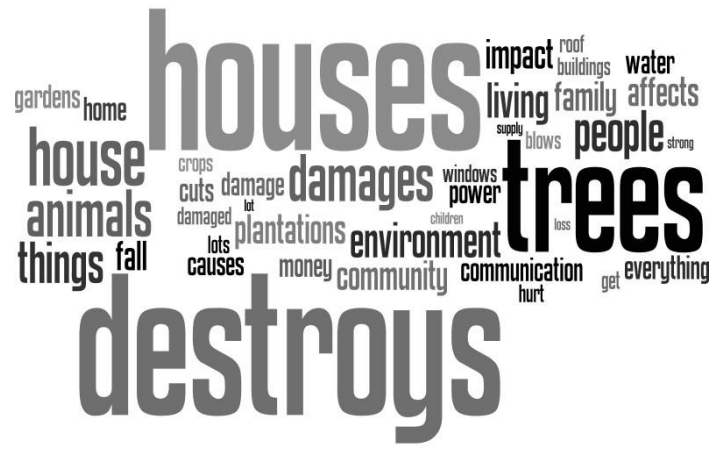

Figure 3. Word cloud summarising 40 most frequently used words in response to question 5, "how do tropical cyclones impact you and your community?", for Fiji (a), Vanuatu (b) and Tonga (c).

the United Nations, 2015). The economic impacts on farming and agriculture were discussed by $24 \%$ of respondents. Notably, the impact of increased prices was mentioned. Cassava (Manihot esculenta), a staple Fijian vegetable, was used as one such example. One respondent told us "the price of cassava usually increases after the cyclone. It usually costs FJD 3 (USD 1.30) for a heap, but after, the price can rise up to FJD 9 (USD 4.10) a heap". The price is subsequently driven upward by the destruction of arable land and shortage of crops. A similar scenario was noted for fish stocks, as fishermen are unable to go to sea because of dangerous and unfavourable conditions. This shortage of product in turn increases the price of fish, another staple food in Fiji. The loss of income during a TC was also discussed, as the survey revealed it is common practice for businesses to cease paying their employees for the duration that trading has stopped. A discussion with a kava (a western Pacific crop; Piper methysticum) producer and vendor in Nadi Market highlighted sig- 
nificant economic losses after Cyclone Daphne (March/April 2012), with a loss of earnings and damaged/destroyed crops totalling approximately USD 8500. A post-disaster report of TC Evan (December 2012) noted that the loss of earnings for agricultural workers was significantly high, with over $50 \%$ of Fiji's loss of earnings coming from this sector alone (GOF, 2013). The sharp increase in the price of housing material after a TC event was also mentioned as hampering the rebuilding process.

\subsubsection{Vanuatu}

A significant number of Ni-Vanuatu respondents (58\%) said that damage to housing and property was a serious impact of TC activity. Specifically, surveys highlighted recent TCinduced flooding as a specific example of this damage. Although more respondents discussed the economic impacts associated with TC activity (29\%) compared to Fiji (24\%), responses from Vanuatu were notably more succinct. Those who did discuss the economic impacts mentioned increased food prices, limited access to money after a TC and few or no insurance policies to help rebuild homes. Recently, the impacts of TC Pam caused widespread destruction, which temporarily ceased kava and copra (dried coconut kernels) cultivation and had a significant impact on the agricultural sector. Losses of up to VUT 6.1 billion $^{2}$ (USD 54 million) and subsequent shortage of food increased food prices by up to 3 times its normal price; a head of cabbage reportedly rose from VUT 100 (USD 0.89) to VUT 300 (USD 2.67) after the event (World Bank, 2015).

Vanuatu's susceptibility to frequent TC events, relatively low GDP per capita, medium HDI index and heavy dependence on agriculture (which in 2015 accounted from $25 \%$ of Vanuatu's GDP; World Bank, 2015) makes this island nation incredibly vulnerable to a TC. If little money is available to rebuild, stronger and more permanent structures may not be possible; therefore the only alternative is to rebuild cheaper, weaker and less permanent structures. A typical outhouse building in the village of Mele Maat (Fig. 4) has tyres and other heavy objects on the roof to protect it from heavy winds. This image highlights the fragility of some structures, many of which were scattered throughout the village.

Only one respondent mentioned the impact on health, particularly during the subsequent flooding which provided the necessary conditions for the spread of malaria, diarrhoea, flu and fever, which provides a challenge for the aged and incapacitated to seek help given the damaged infrastructure.

\subsubsection{Tonga}

Responses from Tonga incorporated many of the impacts discussed by respondents in Fiji and Vanuatu. Damage to housing and personal property (68\%), farming ( $40 \%)$, infrastructure $(15 \%)$ and the economic impacts of TCs $(9 \%)$ were all

\footnotetext{
2100 VUT $=0.89$ USD - correct as of 14 January 2016
}

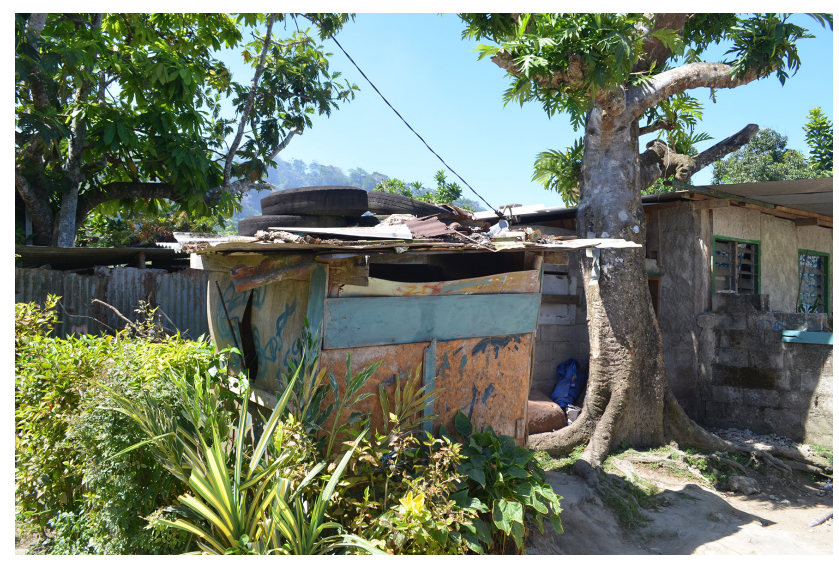

Figure 4. A typical outhouse in Mele Maat village, Efate, Vanuatu. Photo taken: 10 October 2013 by Andrew Magee.

mentioned. An emphasis was placed on personal safety, including fatalities, shock and disruption due to TCs. Many responses highlighted that houses are not strong enough to withstand the strength of TCs, with limited money to rebuild. TC Ian (January 2014) was the most powerful TC to hit Tonga (gusts up to $300 \mathrm{~km} \mathrm{~h}^{-1}$ ). The island group of Ha' apai (200 km northeast of Nuku'Alofa) was most severely affected. Total damage and loss was reported to be TOP 99 mil$\operatorname{lion}^{3}$ (USD 42 million), with the total destruction of $80 \%$ of homes (Asian Development Bank, 2014). The destruction of trees and plantations, specifically banana (Musa), breadfruit (Artocarpus altilis), mango (Mangifera indica) and coconut (Cocos nucifera) were all mentioned by respondents. During TC Ian, $95 \%$ of crops in Ha' apai were damaged, including $99 \%$ of banana plantations (FAO, 2014).

\subsection{TC-related adaptation strategies}

This section explores adaptation strategies across the FVT region by understanding (i) the delivery and quality of TC information, (ii) how individuals prepare for a TC event and (iii) whether individuals use natural indicators of TC activity.

\subsubsection{Delivery and quality of TC Information}

Question 6, "how do you get information when a tropical cyclone is about to hit?", aimed to understand how people receive TC-related information. This open question allowed participants to report more than one answer, and as such, the sum percentage of responses for each nation exceeds $100 \%$. Responses varied considerably according to nation and age group (Table 3 and Fig. 5). Responses highlighted that radio was the most popular way to receive TC broadcasts (FVT: 79,88 and $93 \%$ of respondents respectively). In such developing socioeconomic nations, broadcasting updates through radio provides a cost-effective, participatory method of com-

\footnotetext{
${ }^{3} 1$ TOP $=0.45$ USD - correct as of 14 January 2016
} 


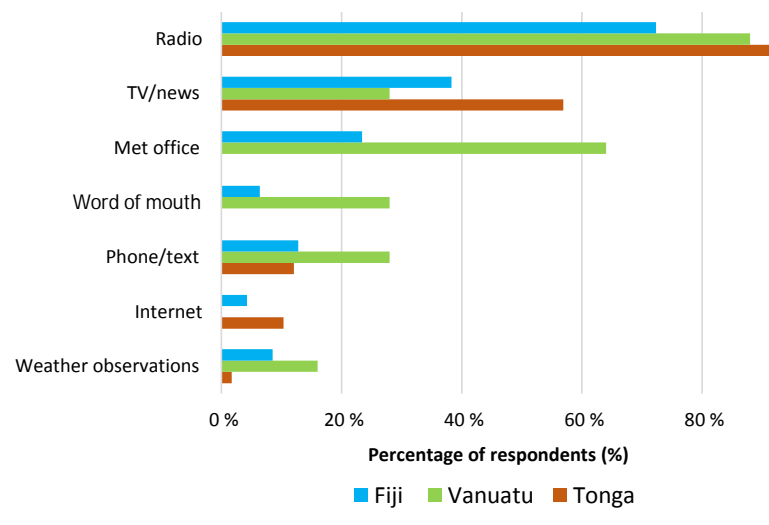

Figure 5. Proportion of responses to question 6: "How do you get your information when a TC is about to hit?"

munication, and for most, a necessity in delivering TC warnings. Other responses included receiving information directly from the meteorological service of each nation (FVT: 23, 60, $0 \%$ respectively), receiving text messages from mobile network providers (FVT: 21, 20, $12 \%$ respectively) or in Tonga, $20 \%$ of respondents said they used the Internet to track the TC event and follow TC warnings.

The types of media used to communicate TC information varied according to age group and nation. For Fiji and Tonga, the use of text message for TC communication was generally answered by the youngest respondents (mean age of $33 \mathrm{Y}$ and 29Y respectively). Weather observations returned the lowest mean age of respondents from Vanuatu (32Y). Word of mouth (55Y), TV (23Y) and weather observations (40Y) returned the highest mean age of FVT respondents respectively. Males were more likely to receive information using text message compared to females across all FVT nations. However, these methods are dependent on having mobile signal, owning a mobile phone and having network/internet access which may not be suited to the more rural outlying islands across the FVT region (which were not included in our survey sample).

Question 7, "is there any other information you need to be better prepared for a tropical cyclone?", assessed whether respondents felt they need any further information to be better prepared and if they find the information satisfactory (Fig. 6). For all three nations, females were more likely to answer that they were satisfied with TC information, whilst men were more likely to suggest it could be improved. Older respondents were more likely to suggest that the information they receive was satisfactory $(42 \mathrm{Y}, 43 \mathrm{Y}$ and $41 \mathrm{Y}$ for FVT respectively) as opposed to those who were dissatisfied with the information (35Y, 35Y and 38Y for FVT respectively).

The majority of respondents in Fiji (64\%) stated that they are satisfied with the information they receive and they don't need any more information to be better prepared. Most stated that warnings are accurate and are generally issued in time to allow for adequate preparation. The remaining $36 \%$ felt

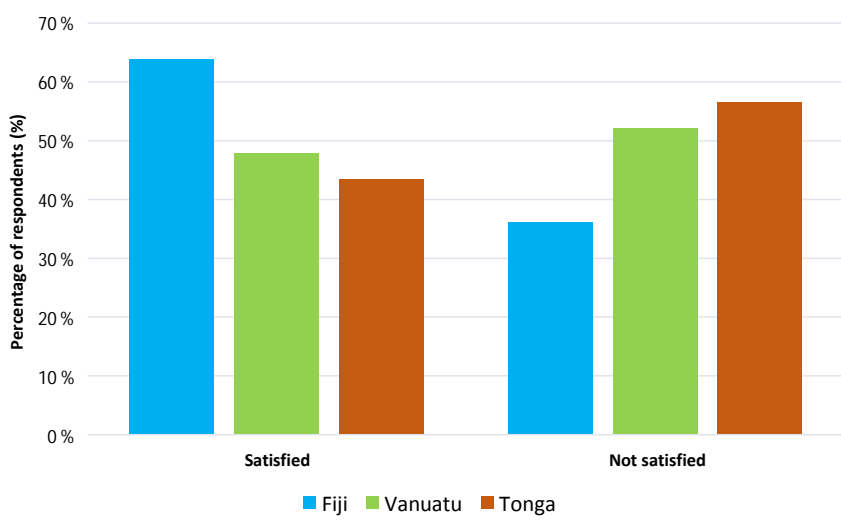

Figure 6. Percentage of responses to question 7: "Is there any other information you need to be better prepared for a TC?"

the information could be improved through more frequent TC updates and more accurate weather reports. For Vanuatu, $48 \%$ of respondents reported that they were satisfied with the TC information they receive. Those who highlighted that more information was needed (52\%) made similar suggestions to those in Fiji and noted the need to improve communication in rural areas/outlying islands (though this was from an urban perspective). More educational programs on how to reduce the impacts of TCs and adaptation measures were suggested as methods that would greatly benefit the population. The majority, $57 \%$, of respondents in Tonga reported they needed more TC information to be better prepared. Many responses mentioned that previously incorrect warnings often came at the wrong time, or came too late, preventing the necessary preparation. It was also suggested that TC information should be tailored for each village/community as their needs can vary, depending on geographical location and the available services. The possibility of using social media and text messages to communicate TC warnings was mentioned by $5 \%$ of respondents. A study of flood risk and public perception in Asia (Motoyoshi, 2006) suggests that while administrative bodies (e.g. meteorological offices) have a responsibility to provide sufficient risk information, the most effective disaster mitigation measures (e.g. insurance policies/home improvements) are implemented when a level of trust exists between the individual and administrative body. The role of trust and its importance in natural disaster preparedness is outlined by Wachinger et al. (2010) and Terpstra (2011).

\subsubsection{Preparing for a TC event}

Question 8, "what do you and your community do to help reduce the impacts of tropical cyclones?", aimed to understand how respondents prepare for a TC once a warning has been issued. Most responses were detailed, outlining the step-bystep actions taken to prepare for a TC. As most responses were similar, this section discusses the actions taken for the 
Table 3. Percentage and mean age of respondents who responded to question 6: "How do you get information about when a tropical cyclone is about to hit?" Blank values suggest no answer has been given.

\begin{tabular}{lllllllllllllllll}
\hline Nation & \multicolumn{2}{c}{ Radio } & \multicolumn{2}{c}{ TV/news } & Met Office & \multicolumn{2}{c}{$\begin{array}{c}\text { Word of } \\
\text { mouth }\end{array}$} & $\begin{array}{c}\text { Phone/text } \\
\text { message }\end{array}$ & \multicolumn{2}{c}{$\begin{array}{c}\text { Internet } \\
\text { observations }\end{array}$} \\
\hline & $\%$ & Age & $\%$ & Age & $\%$ & Age & $\%$ & Age & $\%$ & Age & $\%$ & Age & $\%$ & Age \\
\hline Fiji & $72 \%$ & 37 & $38 \%$ & 38 & $23 \%$ & 43 & $6 \%$ & 55 & $13 \%$ & 33 & $4 \%$ & 50 & $9 \%$ & 39 \\
Vanuatu & $88 \%$ & 36 & $28 \%$ & 43 & $64 \%$ & 39 & $28 \%$ & 37 & $28 \%$ & 39 & - & - & $16 \%$ & 32 \\
Tonga & $91 \%$ & 39 & $57 \%$ & 38 & - & - & - & - & $12 \%$ & 29 & $10 \%$ & 32 & $2 \%$ & 40 \\
\hline
\end{tabular}

FVT as a whole (see schematic in Fig. 7). Two main forms of preparation emerged from this question, property protection actions and personal protection practices.

Respondents spent most time discussing how they prepare their property, making it TC-ready. Initially, preparations begin outside. Gardens and small areas of vegetation are cleared to ensure no loose objects are picked up by high winds. Additionally, any crops that may be of use are saved, which can be consumed or sold. Given the fragility of many houses, participants discussed the process of tying down their roofs and securing their houses at length. Depending on the conditions of the roof, heavy objects (such as tyres or sandbags) are often placed on top to protect the roof from strong winds (see Fig. 4). Shutters may be placed on the windows to protect them from high winds and flying objects.

The preparation of food, water and other consumables was also discussed. Dry food provisions including biscuits, flour and sugar and long-date goods, such as tinned foods, are collected. A working radio, first aid kit, torch and a cyclonetracking map were also identified as important necessities when waiting out the storm, defined as a $72 \mathrm{~h}$ kit in Tonga. Safe public buildings on higher ground, such as churches, schools and community centres, are generally open to residents if they feel their home cannot withstand the impact of the TC. Respondents were very much focused on helping others prepare, particularly those with a disability or those of age who may be less able to prepare. Unlike previous responses, no gender-specific trends were observed.

\subsubsection{Natural indicators of TC activity}

The final question of the survey was open-ended, asking participants if they had anything else they wished to share. It was found that many respondents wanted to share weatherrelated TK, specifically changes in plant or animal activity. A large number of respondents noted a relationship between increased fruit yields and TC activity. In particular, harvests of mangos and breadfruit were noted as fruits that were in abundance preceding the TC season. The shape of tomatoes (Solanum lycopersicum) were also mentioned as a sign of potential TC activity (they are often smaller in size and can fall from the vine earlier than usual). Many respondents mentioned seeing birds native to smaller island groups (e.g. Ma- manuca island group) flying overhead the mainland, and cattle and dogs being very vocal in the days leading to a TC event. The quantity and variety of fish preceding a TC event was also noted as being significantly lower than normal; particularly barracuda, a popular catch, is significantly reduced and crabs are reportedly washed ashore. A number of respondents also mentioned bee activity and the movement of their hive as a positive indicator of TC activity. Generally, and under normal weather conditions, bees build their hives on branches close to the ground. However, before a TC, it is reported that bees can often relocate their hive to higher ground or branches much higher above ground level (away from flooding). Fijians also discussed how using their own observational skills and experiences can be a useful and accurate metric of TC behaviour. Unrelenting hot and humid conditions throughout the day and night are a telltale sign of a future TC event, coupled with unsettled ocean/atmospheric conditions. The potential use of TK to improve TC forecasting will be explored further in Sect. 4.

\section{Discussion}

This discussion addresses the wider significance of the survey findings and outlines the potential to improve adaptation practices for small island states (SISs) through the development of a multidimensional TC forecasting tool incorporating the lessons learned from this study.

\subsection{Awareness of TCs and their associated impacts}

The impacts associated with natural disasters are more severe in developing nations compared to developed nations (Alexander, 1993), exacerbated by rapid urbanisation and the economic characteristics of the nation (El-Masri and Tipple, 2002). The survey results highlighted a significant awareness amongst the FVT population of what to do in the face of a TC, the steps that must be followed to become disasterready and how to prioritise each task (see Sect. 3.3.2). However, there was a distinct lack of awareness about the weather phenomena underpinning a TC. The small island developing economies of FVT, coupled with the spread of islands over a large geographical area, means that cost-effective, accessible 


\section{Adaptive strategies to} reduce impact of TC event

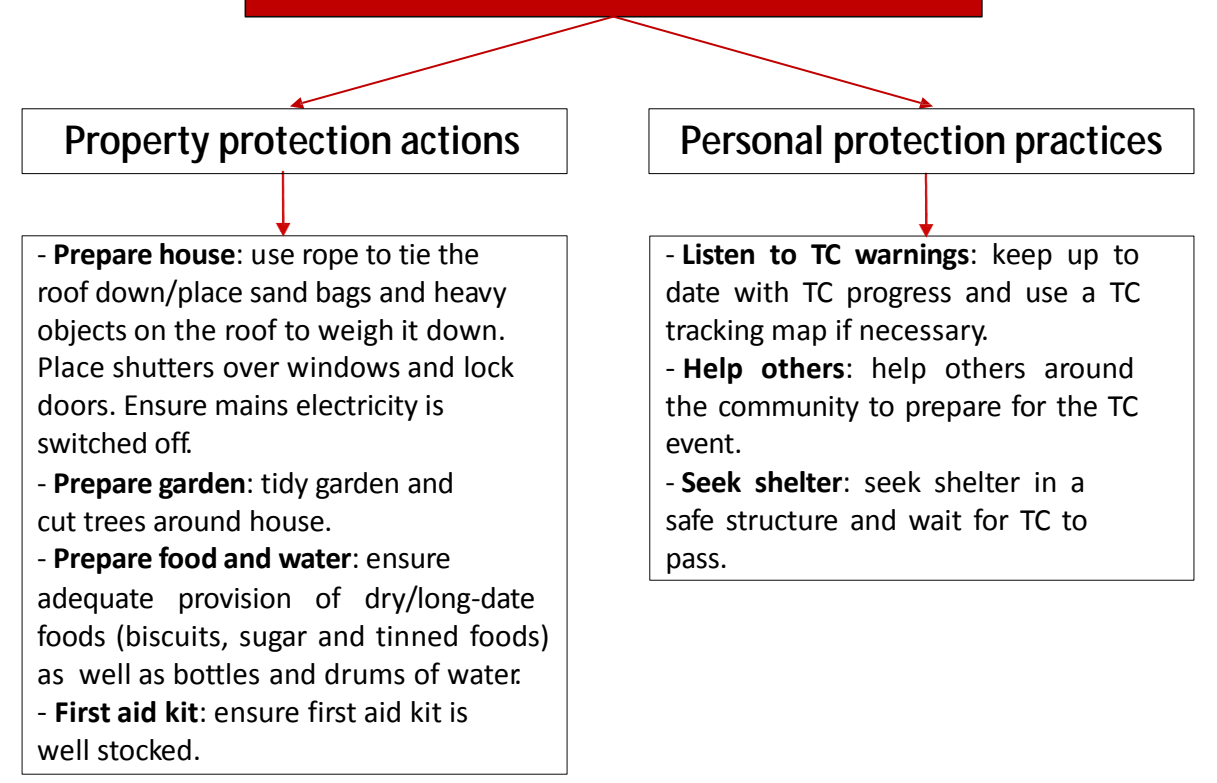

Figure 7. Schematic summarising methods of preparation after a tropical cyclone warning has been issued.

communication and education is required to enable successful disaster management and adaptation strategies.

Recent work has been carried out to enable capacity building and increased awareness of weather-related issues through education programs in the SWP (though none are specifically focused on tropical cyclones). Two such programs, Cloud Nasara and Climate Crabs are a collaboration between the Red Cross and the Australian government's Pacific-Australia Climate Change Science and Adaptation Planning (PACCSAP) program. Cloud Nasara and Climate Crabs are aired on TV and during community education outreach programs which explain various weather extremes caused by El Niño/Southern Oscillation (ENSO) in the Pacific. Cloud Nasara is specifically for ni-Vanuatu people, translated into Bislama, French and English (PACCSAP, 2015). A similar framework could be used to provide community education of TCs, how they form and most importantly, what to expect from TC activity in a changing climate. The reliance on television ownership for this sort of capacity building must also be considered with only $58 \%$ of Fijian (World Development Indicators database, 2014), $36 \%$ of niVanuatu (Vanuatu National Statistics Office, 2010) and $72 \%$ of Tongan households owning a television (Tongan Statistics Department, 2008) However this may be somewhat overcome by introducing such programs in schools and during community education events.

As noted in Sect. 3.3.1, numerous responses stated they received text messages to warn them of a developing TC, a response from mostly younger participants of the survey. The recent telecommunications boom in the South Pacific has seen a recent exponential growth in the use of mobile technology, earning the title "[the] Digital Islands" (Cave, 2012). In a study of the use of mobile phone technology, approximately $60 \%$ of the population in the Pacific have access to a mobile phone (as of November 2013), with increases predicted for the future. In 2009, it was reported that three of every four households owned a mobile phone (Vanuatu National Statistics Office, 2009). Utilising this form of technology is one innovative method of easily communicating TC warnings to almost two-thirds of the population. In the case of TC Pam (which occurred after this survey), text messages with updates on the TC were sent by the Vanuatu Meteorological Service every $3 \mathrm{~h}$ while the TC intensified and every hour as the TC approached Vanuatu. It is believed that this measure (combined with others), helped keep the death toll relatively low for such a major event (ABC News, 2015; World Bank, 2015). Given that the majority of responses from Vanuatu (52\%) and Tonga (57\%) believed the TC information could be improved, capitalising on the increased use of mobile technology may help address the issue.

\subsection{Uncertainty and adaptation to TCs}

The temporal and spatial uncertainty associated with TCs makes planning for TC events extremely difficult, made even more challenging by the developing nature and insularity ex- 
perienced by each island nation. Islands' increased vulnerability and low adaptive capacity (Mimura et al., 2007) makes planning for such events and preparing for the upcoming TC season incredibly important.

Fiji has implemented a range of methods to improve the country's resilience to extreme events and TCs. Examples of this in action include a publication by the Fiji Building Standards Committee (1985). This report outlines numerous design upgrades to homes in a bid to build stronger, more windresistant housing that can withstand TCs (for example, external roof tie-down systems). However, technical guidelines in the document are costly and inaccessible to many. More costeffective technical considerations for building structures in TC-prone areas are outlined by El-Masri and Tipple (2002). In a post-disaster assessment after TC Evan in 2012, many residents stated they would like to use disaster-resilient materials to rebuild their homes; however a lack of financial support prevented this from happening (GOF, 2013).

Schemes to help TC-affected victims rebuild their homes do exist in Fiji. The Fiji National Provident Fund (FNPF) allows members to withdraw up to FJD 5000 (USD 2300) to qualifying households to help rebuild after a TC event. However, this is dependent upon residents having a FNPF account and adequate funds to withdraw. Alternatively, individuals can apply for a TC relief bank loan, which must be repaid with interest. Other programs such as the Housing Assistance and Relief Trust (HART) relocate impoverished families to secure accommodation after a TC event (GOF, 2013). An increase in population and the potential of more intense TCs in the future (Lavender and Walsh, 2011) will see increasing financial pressure placed on these projects, highlighting the potential for more sustainable climate change adaptation practices in the South Pacific.

Capacity building through community engagement programs is the most successful way to educate vulnerable communities of climate extremes and adaptation strategies (PCESD, 2011). In Fiji, a program named Building the National Resilience to Disasters teaches schoolchildren how to be disaster-ready through a booklet containing games and exercises. From 2012, disaster risk reduction (DRR) was made compulsory in the Fijian school curriculum at both the primary and secondary level. Selby and Kagawa (2012) note the innovative student-centred approach Fiji takes to DRR, with routine (three times per term) emergency drill practices and the annual National Disaster Awareness Week. Vanuatu also practices DRR education; however Kagawa and Selby (2012) noted the haphazard structure of DRR in the current curriculum and the limited knowledge of the subject area amongst teachers. SPREP (2013) also highlights that DRR has been introduced into Tonga's national curriculum.

Forward-thinking methods of disaster resilience and adaptation planning have been developed by the Vanuatu Meteorological Service (VMS). Specifically, TC-tracking maps (Fig. 8) are printed in the national phone book by Telecom Vanuatu Ltd (TVL). This aid allows its user to locate a TC based on co-ordinates given, (often used in conjunction with a radio) and gives users the opportunity to understand the spatial extent of the TC event in relation to them. The national phone book also summarises safety and evacuation procedures and provides a wealth of information about TCs including their seasonality, methods of preparation at the start of the TC season, the various types of cyclones and their potential impacts, provided by Vanuatu's National Disaster Management Office (NDMO). The national phone book is distributed free of charge across Vanuatu. Fiji's NDMO has also released a similar cyclone-tracking map, which is also freely available. However, considering the vast spatial extent of the FVT region, the cyclone-tracking map is effectively useless without a radio, a reality in more remote locations across the area. Instead, these more remote regions use TK (further discussed in Sect. 4.3), which is used as a valid source of weather-related information.

\subsection{Improving adaptation practices for small island states (SISs): a conceptual framework}

The Climate and Oceans Support Program in the Pacific (COSPPac) has previously worked to investigate how TK could be utilised to inform seasonal weather prediction in the region (Chand et al., 2014). Building on this work and the initial information obtained during the survey, we propose a twofold method to improve TC-related adaptation practices for the nations of the SWP. First, we explore the potential of utilising weather-related TK with SK and develop a framework to improve TC forecasts for the region, in turn improving adaptation practices and DRR. Second, the lessons learned from this study can be used by practitioners, policymakers and government to implement and/or modify adaptation practices and emergency actions. Given the majority of responses from Vanuatu (52\%) and Tonga (57\%) believed the TC information they receive could be improved, this is a valuable exercise. Figure 9 synthesises the proposed framework to improve adaptation measures and DRR strategies.

The first approach involves the integration of weatherrelated TK and SK. Many studies have demonstrated the usefulness of weather-related TK in improving understanding of environmental prediction and meteorological phenomenon in the South Pacific (e.g. Lefale, 2009; Waiwai and Malsale, 2013; Chand et al., 2014). Examples of weather-related TK include early and more abundant flowering of mango and breadfruit in the harvest season preceding a TC (Whan et al., 2014), the mass movement of birds across a non-native area (Breuner et al., 2013) and changing animal behaviour (Acharya, 2011), indicators that were also mentioned by respondents during the survey.

Moller and Berkes (2004) discuss how utilising qualitative TK data and quantitative scientific knowledge (SK) can benefit and improve our knowledge in many ways (summarised in Table 4). Temporally, longer TK data sets can be merged with shorter SK data sets. Statistically, combin- 


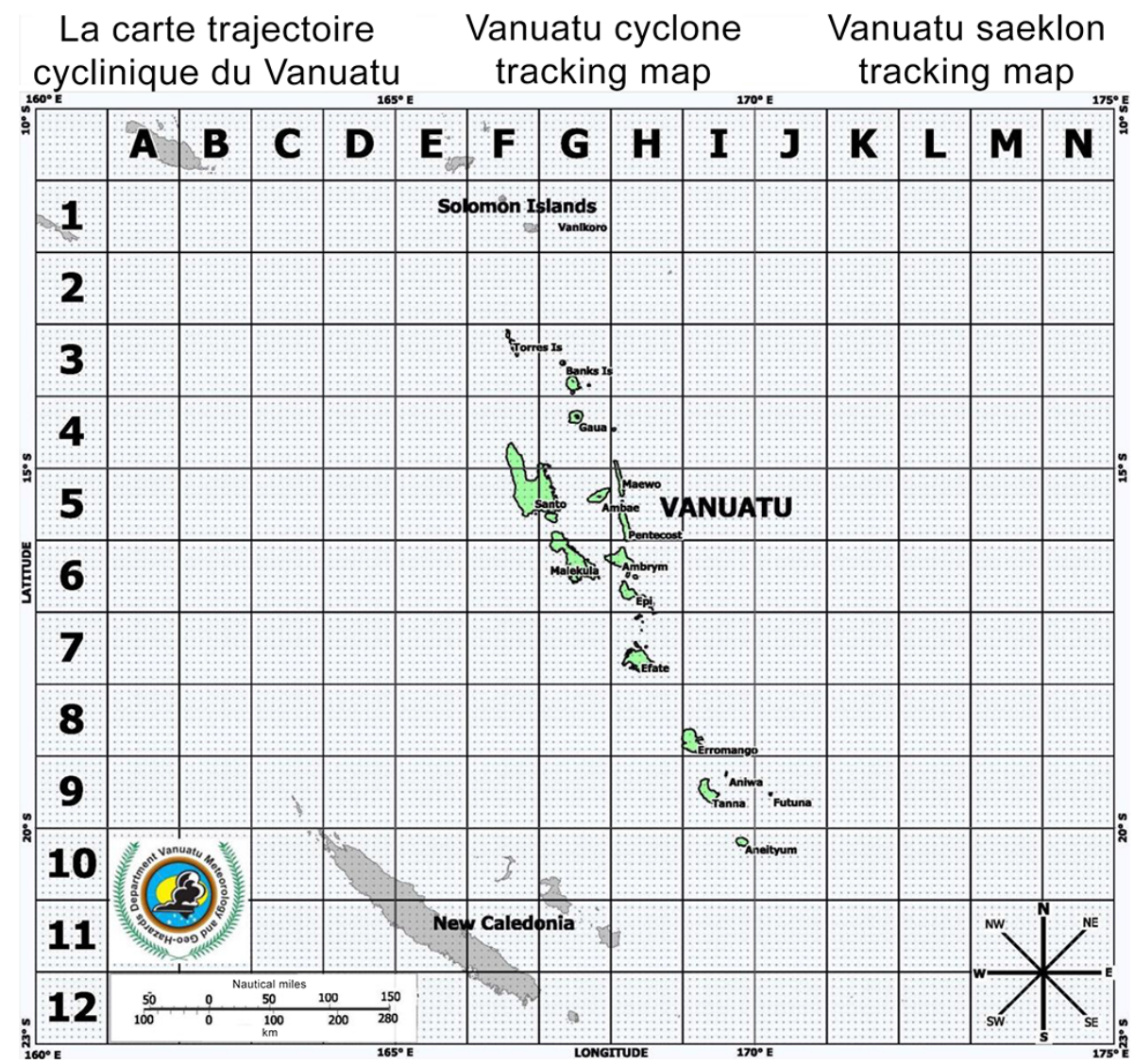

Figure 8. Vanuatu cyclone-tracking map, provided by Vanuatu Meteorology and Geo-hazards Department.

ing the notion of averages (which forms the statistical basis of SK) with extremes (TK) is an insightful way to highlight extreme events and changing patterns. The fact that a theoretical subjective hypothesis (observation) in TK can also be verified by an objective scientific mechanism (SK) suggests that merging TK with SK may be of benefit. Recently, Kijazi et al. (2013) demonstrated the potential of utilising plant-related TK to forecast rainfall in Tanzania, proving that a theoretical hypothesis (ecological indicator used to forecast rainfall) was comparable to observed rainfall conditions (SK). This weather-related TK affords scientists and policymakers the opportunity to incorporate a comprehensive insight into local-scale weather systems, as experienced and informed by generations of indigenous populations.

The logistics of real-time weather-related TK and using the findings to develop a multidimensional TC forecasting tool are explored below (Fig. 9).

1. Depending on the application, a country-by-country assessment of weather-related TK is needed to uncover plant/animal indicators specific to each country.

2. Validation of forecasted conditions using plant/animal indicators (identified in point 1 ) with observed condi- tions and identification of the most effective indicators (see Kijazi et al., 2013).

3. Continuous (real-time) data collection. Examples can be drawn from Waiwai and Malsale (2013), where free mobile phones were distributed to select groups in Vanuatu to collect weather-related TK. A similar scheme that could be introduced, in this case, would be a continual real-time reporting system. Other methods of data collection could include a periodical meeting of individuals from various communities to relay changing environmental conditions.

Amalgamating weather-related TK and SK could result in the development of a multidimensional forecasting tool for SISs. Developing a methodology to translate the qualitative TK data into a homogenous quantitative scientific format and to incorporate it into existing forecasting tools is a significant challenge. More work is needed to establish appropriate strategies of integration for these two distinct entities, appropriate to the SISs of the South Pacific.

The second approach takes the lessons learned from this analysis to directly inform decision makers on respondents' experiences and perceptions of TCs. Information regarding the delivery and quality of TC information may be used by 


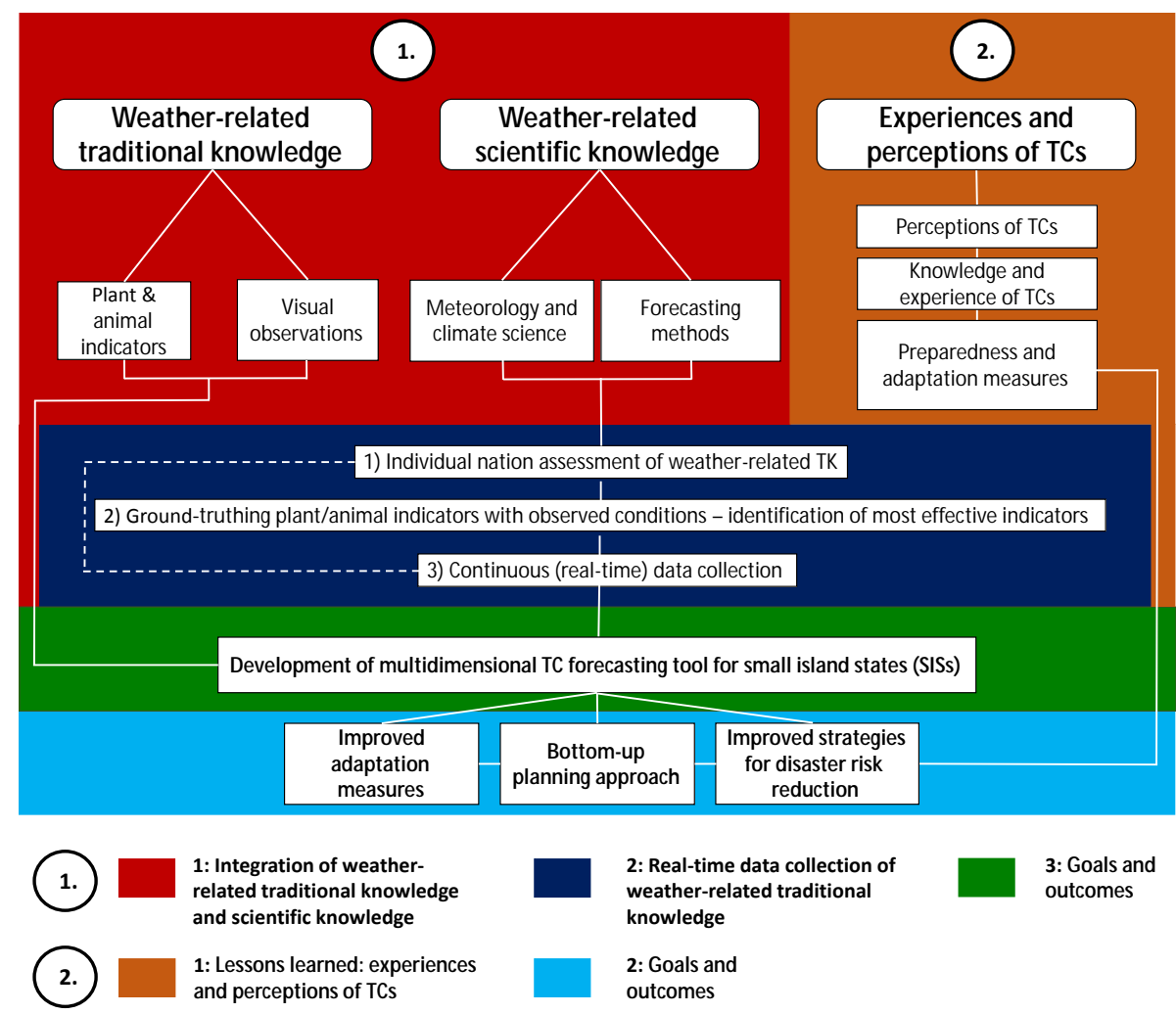

Figure 9. Proposed conceptual framework to improve adaptation measures and strategies for disaster risk reduction for the small island states (SISs) of the Southwest Pacific (SWP).

Table 4. Summary of the differences between traditional knowledge (TK) and scientific knowledge (SK) (adapted from Moller and Berkes, 2004).

\begin{tabular}{lll}
\hline & Traditional knowledge (TK) & Scientific knowledge (SK) \\
\hline Duration of data set & Longer data sets & Shorter data sets \\
Statistical quantification & Extreme events and changing patterns & Averages \\
Type of data set & Qualitative & Quantitative \\
Opinion vs. fact & Subjective hypothesis & Objective mechanisms \\
\hline
\end{tabular}

meteorological centres and emergency management offices to improve their delivery and communication of TC-related information to urban communities. Further, improvements in TC outlooks may result in improved satisfaction scores regarding the quality of TC information received.

\section{Conclusions}

There is no questioning the substantial impact of TCs upon the SISs of the South Pacific and the FVT region. Yet, the forecasting of, and adaptation to TC events is inherently challenging. A notable finding was the divide in respondents who perceived a TC as a weather event in Vanuatu $(80 \%)$ and Tonga (71\%) compared to Fiji (32\%). In particular, responses showed a lack of understanding of the me- teorological conditions associated with TC events, highlighting the opportunity to develop education programs specifically aimed at addressing this knowledge gap. An assessment of the delivery and quality of TC information revealed that the majority of respondents from Vanuatu (52\%) and Tonga $(57 \%)$ need more information to be better prepared, as previous warnings were not considered in a timely way. While the majority of responses from Fiji $(64 \%)$ believed the information they receive is satisfactory, there is still capacity to provide improvements. Interestingly, younger respondents were more likely to suggest that TC information could be improved, whilst older respondents were generally happier with the information they receive. The study also found that the majority of respondents receive TC information through radio; but other methods of telecommunications were men- 
tioned, for example, text messages and the Internet. The recent advances in telecommunication technology and uptake across the FVT will likely increase the use of text messages to relay TC warnings.

The responses highlighted a significant awareness of how to prepare when a TC warning has been issued; yet higherlevel adaptation relating to building design (and funding related to this) requires further consideration to improve resilience. The study also revealed a number of adaptation methods, such as a TC-tracking map in Vanuatu and the inclusion of DRR in the school curriculum, particularly in Fiji. However, it was also highlighted that no single adaptation method is accessible to the entire population of the FVT, given spatial, social and economic limitations.

In this paper we also propose a conceptual framework which integrates weather-related TK with SK with the aim to improve TC outlooks for the region. There are clear benefits of improving adaptation strategies and modifying or developing new strategies for DRR. To achieve this would require additional data collection and homogenisation. Importantly, the findings of this study could be used to aid decision makers and inform climate and disaster management policy.

Acknowledgements. Andrew Magee would like to acknowledge the financial contribution from the University of Newcastle who have provided an International Postgraduate Research Scholarship (UNIPRS), Research Scholarship Central (UNRSC50:50) and contribution from the Eastern Seaboard Climate Change Initiative (ESCCI) for funding his Research Higher Degree (RHD) program and facilitating this research at the University of Newcastle. Further financial assistance from the Commonwealth Scientific and Industrial Research Organisation (CSIRO) and National Climate Change and Research Adaptation Facility (NCCARF) is greatly appreciated. The methodology of this research has been granted approval by the Human Ethics Research Committee (HREC) from the University of Newcastle (approval number: H-2013-0165) in accordance with the National Statement on Ethical Conduct in Human Research (NSECHR, 2007). The authors would also like to thank Mike Waiwai and Philip Malsale from the Vanuatu Meteorology and Geo-hazards Department for their in-country assistance and for providing Fig. 8, and Ofa Faanunu and his team from Tonga Met for their help on the ground. Lastly, a very special thanks to the indigenous Ni-Vanuatu, Fijian and Tongan people who very generously gave their time to take part in this study.

Edited by: P. Tarolli

Reviewed by: two anonymous referees

\section{References}

ABC News: Tropical Cyclone Pam: Why the Vanuatu death toll was so low, [online] available at: http://www.abc.net.au/news/201504-01/explainer3a-why-was-the-vanuatu-death-toll-fromcyclone-pam-so/6363970, last access: 16 September 2015.

Acharya, S.: Presage biology: Lessons from nature in weather forecasting, Indian J. Tradit. Knowl., 10 (January), 114-124, [online] available at: http://nopr.niscair.res.in/handle/123456789/11072 (last access: 1 September 2014), 2011.

Acquah, H. D.: Farmers perception and adaptation to climate change: A willingness to pay analysis, J. Sustain. Dev. Africa, 13, 150-161, 2011.

Alexander, D.: Natural Disasters, Springer Science \& Business Media, 1993.

Anderson, C. L.: Communication and Participation in the Pacific: Lessons for Adaptation to Climate Change \& Variability, in: Climate Change and Variability Symposium of the Pacific Science Congress, Bangkok, Thailand, March 2003, p. 6., 2003.

Ashraf, M. and Routray, J. K.: Perception and understanding of drought and coping strategies of farming households in north-west Balochistan, Int. J. Disaster Risk Reduct., 5, 49-60, doi:10.1016/j.ijdrr.2013.05.002, 2013.

Asian Development Bank: Proposed Grant and Administration of Grant Kingdom of Tonga: Cyclone Ian Recovery Project, [online] available at: http://www.adb.org/sites/default/ files/project-document/80794/48192-001-rrp.pdf, 2014.

Barnett, J.: Adapting to Climate Change in Pacific Island Countries: The Problem of Uncertainty, World Dev., 29, 977-993, doi:10.1016/S0305-750X(01)00022-5, 2001.

Bird, D. K.: The use of questionnaires for acquiring information on public perception of natural hazards and risk mitigation - a review of current knowledge and practice, Nat. Hazards Earth Syst. Sci., 9, 1307-1325, doi:10.5194/nhess-9-1307-2009, 2009.

Breuner, C. W., Sprague, R. S., Patterson, S. H., and Woods, H. A.: Environment, behavior and physiology: do birds use barometric pressure to predict storms?, J. Exp. Biol., 216(Pt 11), 1982-1990, doi:10.1242/jeb.081067, 2013.

Cave, D.: Digital islands: how the Pacific's ICT revolution is transforming the region, in Sydney: Lowy Institute for International Policy, [online] available at: http://lowyinstitute.org/publications/ digital-islands-how-pacifics-ict-revolution-transforming-region (last access: 9 October 2014), 2012.

Chand, S. S. and Walsh, K. J. E.: Tropical Cyclone Activity in the Fiji Region: Spatial Patterns and Relationship to Large-Scale Circulation, J. Climate, 22, 3877-3893, doi:10.1175/2009JCLI2880.1, 2009.

Chand, S. S., Chambers, L. E., Waiwai, M., Malsale, P. and Thompson, E.: Indigenous Knowledge for Environmental Prediction in the Pacific Island Countries, Weather. Clim. Soc., 4, 445-450, doi:10.1175/WCAS-D-13-00053.1, 2014.

Chang'a, L. B., Yanda, P. Z., and Ngana, J.: Indigenous knowledge in seasonal rainfall prediction in Tanzania: a case of the Southwestern Highland of Tanzania, J. Geogr. Reg. Plan., 3, 66-72, 2010.

Chinlampianga, M.: Traditional knowledge, weather prediction and bioindicators?: A case study in Mizoram, Northeastern India, Indian J. Tradit. Knowl., 10 (January), 207-211, [online] available at: http://nopr.niscair.res.in/handle/123456789/11083 (last access: 1 September 2014), 2011.

Connell, J.: Islands at Risk? Environments, Economies and Contemporary Change, Edward Elgar Publishing Limited, Cheltenham, UK, 2013.

Deressa, T. T., Hassan, R. M., and Ringler, C.: Perception of and adaptation to climate change by farmers in 
the Nile basin of Ethiopia, J. Agric. Sci., 149, 23-31, doi:10.1017/S0021859610000687, 2011.

Diamond, H. J., Lorrey, A. M., and Renwick, J. A.: A Southwest Pacific Tropical Cyclone Climatology and Linkages to the El NiñoSouthern Oscillation, J. Climate, 26, 3-25, doi:10.1175/JCLI-D12-00077.1, 2013.

El-Masri, S. and Tipple, G.: Natural Disaster, Mitigation and Sustainability: The Case of Developing Countries, Int. Plan. Stud., 7, 157-175, doi:10.1080/13563470220132236, 2002.

FAO: Cyclone Ian in Ha'apai: Rapid Damage Assessment to the Agriculture and Fisheries Sectors Report, [online] available at: http://reliefweb.int/sites/reliefweb.int/files/resources/ HaapaiCycloneIanAgricultureDamageReportFinalFeb212013. pdf (last access: 5 September 2015), 2014.

Fiji Building Standards Committee: Our War Against Cyclones Guidance To Homeowners on How to Upgrade Existing Homes, Suva, Fiji, 30 pp., 1985.

Food and Agriculture Organisation of the United Nations: Emergency Preparedness and Disaster Risk Reduction in the Pacific, Apia, Samoa, [online] available at: http://www.fao.org/fileadmin/user_upload/sap/docs/INF-PNG002 Emergency Preparedness and Disaster Risk Reduction in the Pacific 2015.pdf, last access: 15 October 2015.

GOF: Fiji and TC Evan: Post-Disaster Needs Assessment, Report Prepared by the Government of Fiji (GOF), 2013.

Green, D., Billy, J., and Tapim, A.: Indigenous Australians' knowledge of weather and climate, Clim. Change, 100, 337-354, doi:10.1007/s10584-010-9803-z, 2010.

Kagawa, F. and Selby, D.: Disaster Risk Reduction Education in Vanuatu, Port-Vila, Vanuatu, [online] available at: http://www.preventionweb.net/files/32504_ vanuatudrrcurriculumbaseline20121.pdf (last access: 27 April 2015), 2012.

Kiem, A. and Austin, E.: Disconnect between science and end-users as a barrier to climate change adaptation, Clim. Res., 58, 29-41, doi:10.3354/cr01181, 2013.

Kijazi, A., Chang'a, L., Liwenga, E., Kanemba, A., and Nindi, S.: The use of indigenous knowledge in weather and climate prediction in Mahenge and Ismani wards, Tanzania, J. Geogr. Reg. Plan., 6, 274-279, doi:10.5897/JGRP2013.0386, 2013.

Klint, L. M., Wong, E., Jiang, M., Delacy, T., Harrison, D., and Dominey-Howes, D.: Climate change adaptation in the Pacific Island tourism sector: analysing the policy environment in Vanuatu, Curr. Issues Tour., 15, 247-274, doi:10.1080/13683500.2011.608841, 2012.

Lavender, S. L. and Walsh, K. J. E.: Dynamically downscaled simulations of Australian region tropical cyclones in current and future climates, Geophys. Res. Lett., 38, 1-6, doi:10.1029/2011WR010620, 2011.

Lefale, P. F.: Ua 'afa le Aso Stormy weather today: traditional ecological knowledge of weather and climate. The Samoa experience, Clim. Change, 100, 317-335, doi:10.1007/s10584-0099722-z, 2009.

Li, G. M.: Tropical cyclone risk perceptions in Darwin, Australia: a comparison of different residential groups, Nat. Hazards, 48, 365-382, doi:10.1007/s11069-008-9269-8, 2009.

Manandhar, S., Vogt, D. S., Perret, S. R., and Kazama, F.: Adapting cropping systems to climate change in Nepal: A cross-regional study of farmers' perception and practices, Reg. Environ. Chang., 11, 335-348, doi:10.1007/s10113-010-0137-1, 2011.

Manandhar, S., Pratoomchai, W., Ono, K., Kazama, S., and Komori, D.: Local people's perceptions of climate change and related hazards in mountainous areas of northern Thailand, Int. J. Disaster Risk Reduct., 11, 47-59, doi:10.1016/j.ijdrr.2014.11.002, 2015.

Mataki, M., Koshy, K., and Nair, V.: Implementing Climate Change Adaptation in the Pacific Islands?: Adapting to Present Climate Variability and Extreme Weather Events in Navua (Fiji), Assessments of Impacts and Adaptations to Climate Change (AIACC), AAIACC Working Paper No. 34, The AIACC Project Office, International START Secretariat, 2000 Florida Avenue, NW Washington DC, 20009, USA, 2006.

McNaught, C. and Lam, P.: Using Wordle as a Supplementary Research Tool, Qual. Rep., 15, 630-643, [online] available from: http://eric.ed.gov/?id=EJ887905 (last access: 8 October 2014), 2010.

Mimura, N.: Vulnerability of island countries in the South Pacific to sea level rise and climate change, Clim. Res., 12, 137-143, 1999.

Mimura, N., Nurse, L., McLean, R. F., Agard, J., Briguglio, L., Lefale, P., Payet, R., and Sem, G.: Small islands, Climate Change 2007: Impacts, Adaptation and Vulnerability. Contribution of Working Group II to the Fourth Assessment Report of the Intergovernmental Panel on Climate Change, edited by: Parry, M. L., Canziani, O. F., Palutikof, J. P., van der Linden, P. J., and Hanson, C. E., Cambridge University Press, Cambridge, UK, 687-716, 2007.

Moller, H. and Berkes, F.: Combining science and traditional ecological knowledge: monitoring populations for comanagement, Ecol. Soc., 9, 2, [online] available from: http: //www.ecologyandsociety.org/vol9/iss3/art2/inline.html (last access: 28 May 2015), 2004.

Mortreux, C. and Barnett, J.: Climate change, migration and adaptation in Funafuti, Tuvalu, Glob. Environ. Chang., 19, 105-112, doi:10.1016/j.gloenvcha.2008.09.006, 2009.

Motoyoshi, T.: Public perception of flood risk and communitybased disaster preparedness, in A better integrated management of disaster risks: Toward resilient society to emerging disaster risks in mega-cities, edited by: Ikeda, S., Fukuzono, T., and Sato, T., 121-134, TERRAPUB and NIED, 2006.

Nishijima, K., Mori, N., Yasuda, T., Shimura, T., Gogon, J. T., Gibson, D., and Jockley, F.: DPRI-VMGD joint survey for Cyclone Pam damages, Port-Vila, Vanuatu, [online] available at: http://www.taifu.dpri.kyoto-u.ac.jp/wp-content/uploads/2015/ 05/DPRI-VMGD-survey-first-report-Final.pdf, last access: 20 October 2015.

NSECHR: The National Health and Medical Research Council, the Australian Research Council and the Australian Vice-Chancellors' Committee, Commonwealth of Australia, Canberra. Report prepared by National Statement on Ethical Conduct in Human Research (NSECHR), [online] available at: http://scholar.google.com/scholar?hl=en\&btnG=Search\&q= intitle:National+Statement+on+Ethical+Conduct+in+Human+ Research\#0 (last access: 3 December 2014), 2007.

Nyong, A., Adesina, F., and Osman Elasha, B.: The value of indigenous knowledge in climate change mitigation and adaptation strategies in the African Sahel, Mitig. Adapt. Strateg. Glob. Chang., 12, 787-797, doi:10.1007/s11027-007-9099-0, 2007. 
PACCSAP: Welcome to the Cloud Nasara, [online] available at: http://www.pacificclimatechangescience.org/animations/ cloudnasara/, last access: 22 October 2015.

PCESD: Community-based adaptation to climate change: A review of good practices in the Pacific, Suva, Fiji, 2011.

Peduzzi, P., Chatenoux, B., Dao, H., De Bono, A., Herold, C., Kossin, J., Mouton, F., and Nordbeck, O.: Global trends in tropical cyclone risk, Nat. Clim. Chang., 2, 289-294, doi:10.1038/nclimate1410, 2012.

Plapp, T. and Werner, U.: Understanding risk perception from natural hazards: examples from Germany, in RISK21 - Coping with risks due to natural hazards in the 21 st century, edited by: Ammann, W. J., Dannenmann, S., and Vulliet, L., 101-109, Routledge, UK, 2006.

Rasmussen, K., May, W., and Birk, T.: Climate change on three Polynesian outliers in the Solomon Islands: impacts, vulnerability and adaptation, Geogr. Tidsskr. - Danish J. Geogr., 109, 1-13, doi:10.1080/00167223.2009.10649592, 2009.

Robinson, J. B. and Herbert, D.: Integrating climate change and sustainable development, Int. J. Glob. Environ. Issues, 1, 130-149, 2011.

Roder, G., Ruljigaljig, T., Lin, C. W., and Tarolli, P.: Natural hazards knowledge and risk perception of Wujie indigenous community in Taiwan, Nat. Hazards, 81, 1-22, doi:10.1007/s11069015-2100-4, 2015.

Salinger, M. J. and Lefale, P.: The Occurrence and Predictability of Extreme Events over the Southwest Pacific with Particular Reference to ENSO, in: Natural Disasters and Extreme Events in Agriculture, 39-49, Springer Berlin Heidelberg, 2005.

Selby, D. and Kagawa, F.: Disaster risk reduction in school curricula: case studies from thirty countries, Geneva/Paris: UNICEF/UNESC, [online] available at: http://www.unicef.org/ education/files/DRRinCurricula-Mapping30countriesFINAL. pdf (last access: 2 March 2015), 2012.

Shoko, K. and Shoko, N.: Indigenous Weather Forecasting Systems: A Case Study of the Abiotic Weather Forecasting Indicators for Wards 12 and 13 in Mberengwa District Zimbabwe, Asian Soc. Sci., 9, 285-297, doi:10.5539/ass.v9n5p285, 2013.

Solberg, C., Rossetto, T., and Joffe, H.: The social psychology of seismic hazard adjustment: re-evaluating the international literature, Nat. Hazards Earth Syst. Sci., 10, 1663-1677, doi:10.5194/nhess-10-1663-2010, 2010.

SPREP: Tonga integrates climate change and disaster risk management into education, Secr. Pacific Reg. Environ. Program., available at: https://www.sprep.org/climate-change/ tonga-integrates-cc-and-drm-into-education (last access: 22 October 2015), 2013.

Terpstra, T.: Emotions, Trust, and Perceived Risk: Affective and Cognitive Routes to Flood Preparedness Behavior, Risk Anal., 31, 1658-1675, doi:10.1111/j.1539-6924.2011.01616.x, 2011.

Tongan Statistics Department: Tonga 2006 Census of Population and Housing, 2008.
Udmale, P., Ichikawa, Y., and Manandhar, S.: Farmers' perception of drought impacts, local adaptation and administrative mitigation measures in Maharashtra, Int. J. Disaster Risk Reduct., 10, 250-269, doi:10.1016/j.ijdrr.2014.09.011, 2014.

United Nations Development Program: Human Development Report 2015, [online] available from: http://hdr.undp.org/sites/ default/files/hdr_2015_statistical_annex.pdf, last access: 10 October 2015.

Vanuatu National Statistics Office: National Census of Population and Housing, Port Vila: Ministry of Finance and Economic Management, 2009.

Vanuatu National Statistics Office: Vanuatu 2009 National Population and Housing Census - Basic Tables Report, Volume 1, PortVila, Vanuatu, [online] available at: http://www.pacificdisaster. net/pdnadmin/data/original/VUT_2009_Census_ReportV1.pdf (last access: 30 November 2014), 2010.

Vedwan, N. and Rhoades, R.: Climate change in the Western Himalayas of India: a study of local perception and response, Clim. Res., 19, 109-117, doi:10.3354/cr019109, 2001.

Wachinger, G., Renn, O., Domènech, L., Jakobson, I., Kuhlicke, C., Lemkow, L., Pellizzoni, L., Piriz, A., Saurí, D., Scolobig, A., Steinführer, A., Supramaniam, M., Whittle, R., Bianchizza, C., Coates, T., and Marchi, B.: Risk perception and natural hazards, Stuttgart, [online] available at: http://caphaz-net.org/ outcomes-results/CapHaz-Net_WP3_Risk-Perception2.pdf (last access: 1 September 2015) 2010.

Wachinger, G., Renn, O., Begg, C., and Kuhlicke, C.: The Risk Perception Paradox-Implications for Governance and Communication of Natural Hazards, Risk Anal., 33, 1049-1065, doi:10.1111/j.1539-6924.2012.01942.x, 2013.

Waiwai, M. and Malsale, P.: National Workshop on Traditional Knowledge of Weather and Climate, Lounamua Village, Pele Islands, Efate, Vanuatu (15-19 April 2013), 2013.

Whan, K., Alexander, L. V., Imielska, A., McGree, S., Jones, D., Ene, E., Finaulahi, S., Inape, K., Jacklick, L., Kumar, R., Laurent, V., Malala, H., Malsale, P., Pulehetoa-Mitiepo, R., Ngemaes, M., Peltier, A., Porteous, A., Seuseu, S., Skilling, E., Tahani, L., Toorua, U., and Vaiimene, M.: Trends and variability of temperature extremes in the tropical Western Pacific, Int. J. Climatol., 34, 2585-2603, doi:10.1002/joc.3861, 2014.

World Bank: Not if, but when: Adapting to natural hazards in the Pacific Island Region, A policy note, The World Bank, East Asia and the Pacific Region, Pacific Islands Country Management Unit, Washington, D.C., 2006.

World Bank: Post-Disaster Needs Assessment: Tropical Cyclone Pam, Post-Vila, Vanuatu, 2015.

World Development Indicators database: Countries Compared by Media >Households with television. International Statistics at http://www.nationmaster.com/, [online] available at: http://www.nationmaster.com/country-info/stats/Media/ Households-with-television (last access: 11 January 2016), 2014. 